\title{
Home delivery complicated with puerperal sepsis in urban India
}

\author{
Niranjan N. Chavan, Pradnya R. Changede*, Shaista R. Khan
}

\begin{abstract}
Department of Obstetrics and Gynaecology, Lokmanya Tilak Municipal Medical College and General Hospital,
\end{abstract} Mumbai, Maharashtra, India

Received: 03 March 2016

Accepted: 30 March 2016

*Correspondence:

Dr. Pradnya R. Changede,

E-mail: pradnyachangede@gmail.com

Copyright: () the author(s), publisher and licensee Medip Academy. This is an open-access article distributed under the terms of the Creative Commons Attribution Non-Commercial License, which permits unrestricted non-commercial use, distribution, and reproduction in any medium, provided the original work is properly cited.

\begin{abstract}
Puerperal sepsis is among the leading and preventable causes of maternal morbidity and mortality worldwide and especially in developing countries. We report an interesting case of home delivery complicated with puerperal sepsis, who required obstetric hysterectomy. Inspite of being a resident of an urban metropolitan city patient had no access to antepartum, intrapartum or even postpartum care. She presented on day eleven postpartum to our institute by which time, her condition had progressed to frank pyoperitoneum and severe anaemia. Urgent, aggressive intervention in the form of evacuation of intra-abdominal pus, obstetric hysterectomy with oophorectomy saved her life.
\end{abstract}

Keywords: Puerperal sepsis, Home delivery, Obstetric hysterectomy, Pyoperitoneum, Maternal mortality

\section{INTRODUCTION}

Any infection of the genital tract after delivery is generally known as puerperal infection. Obstetric shock and death resulting from puerperal sepsis was the traditional norm worldwide prior to the introduction of aseptic techniques and antibiotics, following which maternal death rates reduced in the developed world. However, puerperal sepsis is still a dominant problem in developing countries and continues to present a significant risk of obstetric morbidity and mortality in women of these regions.

India is second only to Nigeria in recording the highest number of maternal deaths in any single country, accounting for 45,000 maternal deaths in $2015 .^{1}$ Sepsis is the third leading cause of direct maternal death in developing countries as per WHO (World Health Organization) systematic analysis of $2014 .^{2}$

Up to $27 \%$ of intensive care unit (ICU) admissions of obstetric patients result from puerperal sepsis. ${ }^{3}$ The contribution of sepsis as a cause of maternal mortality is between $4.7 \%$ in developed countries and $10.7 \%$ in developing countries.

\section{CASE REPORT}

28 year old female, Para 2, Living 2, postpartum day 11 of full term vaginal home delivery presented to our tertiary care hospital with complaints of intermittent high grade fever with chills, abdominal pain and malaise of 10 days duration (symptoms started immediately postpartum). Patient delivered on a roadside footpath (which was home to her) by an untrained birth attendant. A full term female child was born who cried immediately at birth. On examination, her temperature was 101 degree $\mathrm{F}$, pulse was 100 beats per minute and blood pressure was $100 / 70 \mathrm{~mm} \mathrm{Hg}$. She was conscious, oriented but appeared severely pale. Her cardiovascular and respiratory system examinations were normal.

On abdominal examination, tenderness was present in the lower abdomen (hypogastrium and both iliac fossa), uterus was 14 weeks size. On speculum examination, foul smelling lochia with creamish coloured pus flakes was seen. On pervaginal examination, subinvoluted uterus of 14 weeks size and uterine tenderness was present.

Ultrasonography of abdomen and pelvis showed moderate free fluid in the pelvis, bulky postpartum 
uterus, bulky ovary of $5.8 \times 5.1 \mathrm{~cm}$ (oophoritis), endometrial thickness of $5 \mathrm{~mm}$ with mild hepatospleenomegaly. Tapping of this free fluid revealed frank pus. Her haemoglobin was $4.5 \mathrm{gm} \%$, white cell count was 21,000 cells/cumm, platelet count was $3,12,000 /$ cumm. Her serum creatinine was $1.2 \mathrm{mg} \%$, INR was 1.13 . X-ray chest was normal.

Immediate resuscitative measures were started which included packed cell transfusions and broad spectrum intravenous antibiotics (Piperacillin + Tazobactum, Gentamicin, Metronidazole). Patient was then taken up for exploratory laparotomy.

\section{Intra-operative findings were:}

- $250 \mathrm{cc}$ of frank pus (Figure 1).

- Uterus of 14 weeks size.

- Enlarged left ovary, $5 \times 5 \mathrm{~cm}$, firm, covered with a thick layer of pus (Figure 2).

- Right ovary appeared normal.

- Both fallopian tubes appeared oedematous, firm, enlarged.

- Liver, spleen, bowel appeared normal.

Patient underwent obstetric hysterectomy, bilateral salpingectomy with left oophorectomy (Figure 3). Evacuated pus was sent for culture and sensitivity. On cut section of the specimen of uterus and ovary frank pus was seen extruding through the cavity. Intra-abdominal drain was inserted. She was transfused with total 4 units each of packed cells and fresh frozen plasma. Postoperatively, she had significant pus drainage continuously for next seven days. Drain was removed on postoperative day 9 once drain output became insignificant.

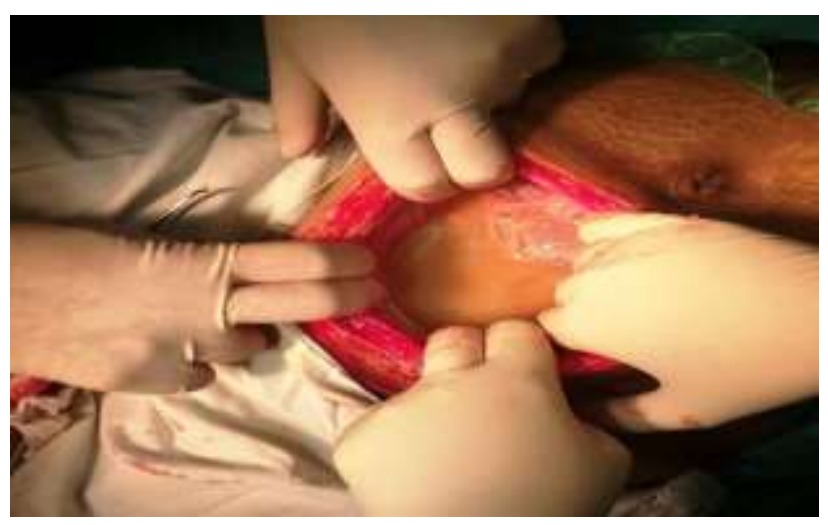

Figure 1: Pyoperitoneum. 250cc of frank pus seen on opening the pelvic cavity.

Grams staining of pus collected from abdominal cavity revealed a few gram negative bacilli. Zeil-Neilson staining of pus showed absence of acid fast bacilli. Acinetobacter calcoceticus and Klebsiella pneumonia (ESBL) were isolated on culture. On antibiotic sensitivity both organisms were sensitive to following antibiotics: Meropenem, Imepenem and Levofloxacin. Patient was started on injectable Meropenem in view of culture sensitivity report. Full length wound gape occurred on suture removal on day 14 for which she underwent secondary suturing on day 22. Her further postoperative course was uneventful. HPR - Uterus showed subepithelial lympho-plasmacytic infitrate.

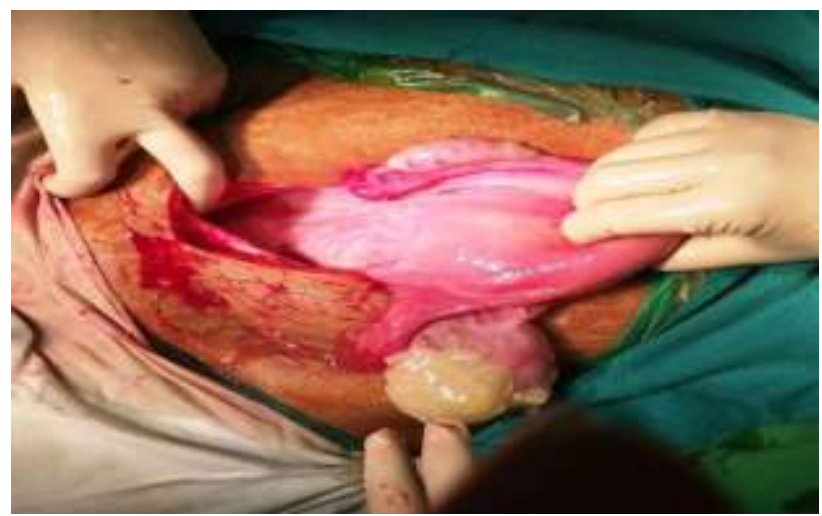

Figure 2: Enlarged left ovary covered with a thick layer of pus.

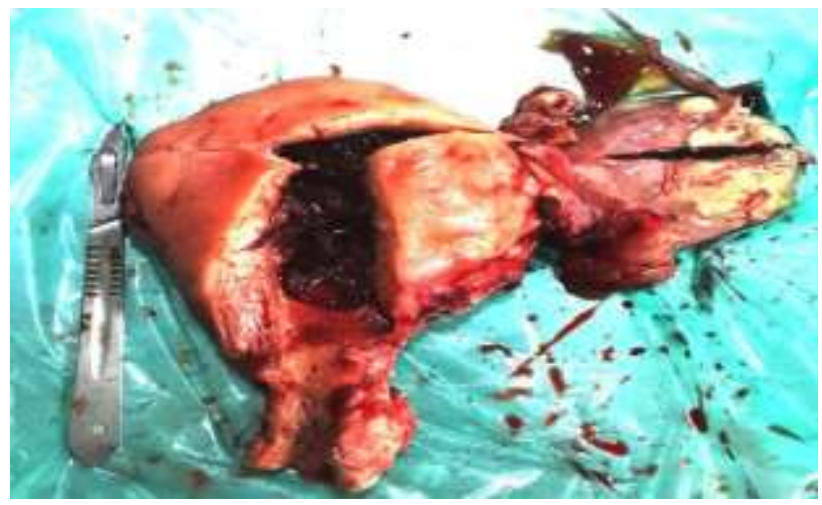

Figure 3: Cut open specimen after total hysterectomy. Blood clots and pus seen in the uterine cavity and in the enlarged left ovary.

\section{DISCUSSION}

As per World Health Organisation, any genital tract infection, with at least two of the following : pelvic pain, fever, abnormal vaginal discharge, abnormal odour of discharge, subinvolution of uterus, occurring at any time between rupture of membranes or labour, and postpartum day forty two, is known as puerperal sepsis. ${ }^{4}$

The factors predisposing to the development of sepsis include delivery in unhygienic conditions, low status or education of women, poor nutrition, anaemia, prolonged rupture of membranes, long labour, multiple vaginal examinations in labour, caesarean section, instrumental delivery, retained products of conception within the uterus and postpartum haemorrhage. ${ }^{5}$

Peritonitis, abscess formation, pelvic thrombophlebitis with consequent pulmonary embolism, septicaemia, endotoxic shock are the immediate complications seen. 
Late sequelae include chronic pelvic inflammatory disease, ectopic pregnancy and secondary infertility. ${ }^{6}$ There is also an association with early onset neonatal sepsis. ${ }^{6}$

The bacterial organisms most prevalent for severe infection include: Streptococcus pyogenes or group A beta haemolytic streptococci, Escherichia coli, Staphylococcus aureus, Streptococcus pneumonia, methicillin-resistant S. aureus (MRSA), Clostridium septicum and Morganella morganii. ${ }^{7}$

Our patient was multiparous, unregistered, unimmunized, illiterate of very low socioeconomic status and poor nutrition. She delivered on a roadside footpath by an untrained birth attendant, with no antibiotic cover. By the time, she sought medical care i.e. $11^{\text {th }}$ day post-delivery; she had developed full-blown puerperal sepsis with pelvic abscess. Early surgical intervention with aggressive therapy was life saving for our patient.

Institutional delivery with proper antenatal and postnatal care is the need of the hour - which is still to be fully realized even in urban India. Presently, India has managed to have three fourth of deliveries occurring in institutions conducted by the qualified professionals which is a promising sign. ${ }^{8}$

However such case reports remind us that we still have a long way to go to ensure $100 \%$ institutional delivery rate.

Funding: No funding sources

Conflict of interest: None declared

Ethical approval: Not required

\section{REFERENCES}

1. WHO, UNICEF, UNFPA, The World Bank and the United Nations Population Division. Trends in maternal mortality: 1990 to 2015. Geneva: World Health Organization. 2015:19.

2. Say L, Chou D, Gemmill A, Tunçalp Ö, Moller AB, Daniels JD, et al. Global Causes of Maternal Death: A WHO Systematic Analysis. Lancet Global Health. 2014;2(6):e323-33.

3. Gombar S, Ahuja V, Jafra A. A retrospective analysis of obstetric patient's outcome in intensive care unit of a tertiary care center. Journal of Anaesthesiology, Clinical Pharmacology. 2014;30(4):502-7.

4. The prevention and management of puerperal infections: report of a technical working group 1992. Geneva: World Health Organization; 1995:3 http://apps.who.int/iris/bitstream/10665/59429/1/WH O_FHE_MSM_95.4.pdf. Acessed at 20 January 2016.

5. Maharaj D. Puerperal Pyrexia: a review. Part II. Obstet Gynecol Surv. 2007;62(6):400-6.

6. Hussein J, Walker L. Puerperal sepsis in low and middle income settings: Past, present and future in maternal and infant death: Chasing Millennium development Goals Edited by kehoes, Neilson JP, Norman JE, London: RCOG Press. 2010:131-147.

7. Royal College of Obstetricians and Gynaecologists (RCOG). Bacterial sepsis following pregnancy 64b April 2012. RCOG Green top Guidelines. London: RCOG Press; 2012b. http://www.rcog.org.uk/womens-health/clinicalguidance/sepsis-following-pregnancy-bacterialgreen-top-64b. Accessed 20 January 2016.

8. Census of India: SRS Statistical report 2012, Chapter 3 Estimate of fertility indicators. http://www.censusindia.gov.in/vital_statistics/SRS_ Report_2012/10_Chap_3_2012.pdf. Accessed 20 January 2016.

Cite this article as: Chavan NN, Changede PR, Khan SR. Home delivery complicated with puerperal sepsis in urban India. Int J Reprod Contracept Obstet Gynecol 2016;5:1660-2. 